\title{
Students' choices between typing and handwriting in examinations
}

Nora Mogey, John Cowan, Jessie Paterson, Mike Purcell

\section{Biography of authors}

Nora Mogey works in the Institute for Academic Development at The University of Edinburgh. She is interested in different ways that technologies can be used to improve the student experience, and particularly in their uses to support assessment.

Contact details: The Institute for Academic Development, 7 Bristo Square, Edinburgh EH8 9AL; Tel 0131651 4518; e-mail Nora.Mogey@ed.ac.uk

John Cowan is Professor Emeritus of Learning Development of the Open University. Nowadays he is a part-time tutor on a range of face-to-face and distance learning courses, with a special interest in self-assessment and formative assessment.

Contact details: 34 Caiystane Avenue, Edinburgh EH10 6SH. Tel 0131445 3196; e-mail J.Cowan@napier.ac.uk

Jessie Paterson works in the School of Divinity and also has a part-time secondment to the Institute of Academic Development at the University of Edinburgh. For about ten years she has been exploring the use of technology in teaching and learning.

Contact details: School of Divinity, New College, Mound Place, Edinburgh EH1 2LX; Tel 0131 650 7953; e-mail Jessie.Paterson@ed.ac.uk

Mike Purcell is Senior Lecturer in Theology and Ethics. He has a keen interest in the relation of phenomenology and theology, and the phenomenology of religion. Contact details: School of Divinity, New College, Mound Place, Edinburgh EH1 2LX Tel: 0131650 8940; e-mail M.Purcell@ed.ac.uk

Keywords: essay, examination, word processing, handwriting, computer, preparation, choice, time limit,

\begin{abstract}
Keyboarding is a ubiquitous skill for most UK students and most coursework essays must be word-processed. However few examinations, other than for students with disabilities, permit the use of a word-processor. It is not known how students would respond given a free choice between handwriting and word-processing in an essay examination. This study reports the findings when students were encouraged to choose between these methods of composition for an examination. Few opted to word process; the students' reactions immediately after the examination were obtained. The demands of essay examinations as compared with assignments are identified and discussed and implications for future enquiries are considered.
\end{abstract}

\section{Students' choices between typing and handwriting in examinations}

The issue of 'fairness' in an examination is complex. Typically students select a small number of questions from those on the paper; but the questions differ in difficulty and the markers differ in their severity (Lamprianou, 2008). The examination questions are drawn from only a subset of the syllabus, in a manner often judged by students to be arbitrary and irrelevant (Struyven et al, 2002). It is known that students both learn and recall better when relaxed (Cassaday et al, 2002); but one student relaxes to music, another needs silence, while yet another needs the smell of roasting coffee. Some students naturally perform better in the morning, others in the afternoon (Callan, 1999; Hartley \& Nicholls 2008). A student may be 
sick or tired or may under perform simply because of the stressful nature of an examination; but students are not equally likely to use these feelings as grounds for special consideration (Chamorro-Premuzic \& Furnham, 2002). So the environment in the examination venue potentially becomes a factor in performance and thus in the validity of the assessment.

Essay-type examinations are widely used as a major component of assessment in higher education, in the belief that they evidence students' ability to demonstrate analytical and critical thinking. Surprisingly little concern is expressed that the time-limited context of examinations tends to result in students submitting what is essentially a first draft of their thoughts, and presumably far from their best possible work (Davis et al, 1981). Fluency in writing contributes to an examination essay score, as does subject knowledge (Connelly et al, 2005); but the presentation of subject knowledge is not necessarily correlated with what the student has learned on a particular course nor with the amount of effort the student has expended. Passing or failing an examination is seemingly not dependent on how much is written (Whithaus et al, 2008), nor is the amount written in an examination directly linked to writing speed (Summers \& Catarro, 2003). Thinking time is needed.

There is also the question of the reliability of essay marking, which has mainly been studied for handwritten essays. Even ignoring the thorny issue of variation between markers (Barrett, 1999) and despite markers' stated intentions, there is evidence that there is a tendency to award marks for content knowledge more readily than for argument and structure (Maclellan, 2004). Markers are also known to be influenced, albeit unintentionally, by the way in which a script is presented. When otherwise identical essays are marked, one in a handwritten and one in a typewritten version, then the handwritten version of the script scores marginally higher than the typed version of the same script, (Chen et al, 2011; Horkay et al, 2006; MacCann et al, 2002).

In an era when students are increasingly expected to submit coursework essays and assignments in digital form, it seems inappropriate and anachronistic to insist that they abandon their keyboards when they sit formal examinations. It is some time since Hartley (1993) reviewed the potential of word-processors for changing the ways in which writers generate written text and how they think about their writing when using a keyboard. He discussed whether changing the processes of writing necessarily leads to improvements in writing quality, and in particular raised questions about the use of word-processors in examinations. His concern was that a student writing essays at home using a computer might be disadvantaged in an examination when expected to handwrite. Given the developments in the intervening period, it seems opportune to revisit this matter.

Coursework assignments are fundamentally different to examination essays (Brown, 2010), but it is through the writing of coursework that most students develop their essay writing skills. Typically students will have access to library resources, and they are often required to submit their work in a word-processed form, either digitally or printed. Students approach the task of writing digital coursework essays in a variety of ways. Some make copious notes by hand, prepare several drafts and only type out a final version. Others use a computer throughout the process, and may "plant" key points and then "grow" further associated content around them. Students who review and revise their work often are rewarded with a consequent improvement in their mark (Oliver \& Kerr, 1993; Burke \& Cizek, 2006). In contrast, in an examination, students may not have time to revise their words; hence the ability to handwrite or to type quickly, together with the approach they used to generate an acceptable written response in limited time, although not necessarily the key factors in performance, might become more important. Typically students can type faster than they can handwrite (MacKenzie \& Soukoreff, 2002). Lovett et al (2010) demonstrated that college students writing under timed (but non-examination) conditions wrote significantly more when word processing compared to handwriting. Further they demonstrated that in the case of the word processed texts, length correlated with quality, but that this was not the case for hand written essays.

Allowing the use of computers in essay-type examinations is not new. Arrangements for students with disabilities often include allowing the use of a computer. But to date few universities permit students, other than those with disabilities, to type essay-type examinations; where they do, there is no choice. For mainstream classes, Law schools in 
USA have for many years routinely conducted bar examinations using students' owned laptops; but there is no choice - the option is to type or not to take the examination.

Students are typically risk averse, at least where assessment is concerned (Clifford, 1990, Carless, 2009). Many students demonstrate highly strategic approaches to their study choices (Ramsden, 2003:67), and particularly their preparations for examinations (Miller \& Parlett, 1974). Although they may have little opportunity to influence the time of the examination, or the conditions in the venue, well considered and planned examination strategies include predicting question topics (Miller \& Parlett, 1974), using a greater variety of sources in responses, and deliberately expressing a view known to be inline with that of the marker (Norton \& Hartley, 1986). To elect to type an essay-type examination would be an unquantified risk for many students. The equity of allowing the choice to type or to handwrite might also be questioned. Mogey et al (2010) describe a study where student scripts collected in a mock examination (some originally handwritten and others originally typed) were all transcribed into the opposite format, giving two copies of each examination script. The marks awarded by different markers to the two versions were compared. Overall the impact of the writing medium was not found to introduce a systematic bias to the score.

Where the choice to handwrite or type essay-type examinations has been offered, this has been broadly welcomed by students but the actual take up has been markedly lower than had been anticipated. Students support the suggestion because they recognise that computers are an integral part of modern life, but they express concerns about the reliability of the technology and about their own lack of practice using computers in examinations (Mogey et al 2008). While we know something about student strategies for writing coursework essays by hand (Hounsell, 2005), and the differences in composing processes which may be due to using a word processor (Haas, 1989), until staff and students understand more about the differences between handwriting and typing essay-type examination, it will be hard for students to make reliable decisions (or for staff to offer objective advice) about the better option for them.

This exploratory study was undertaken to try to identify any differences in how students go about writing essay-type examinations compared to coursework essays, and to explore whether allowing students the opportunity to type their essay-type examinations impacted on their examination writing behaviour. Having been required to word-process their assignments, how do students opt to respond to examination questions when permitted to hand write or word-process?

\section{Research Methodology}

A small focus group was held in October 2010. Participation was voluntary; students from all years of one school (Divinity) were invited to contribute. In order to create some prompts for discussion, one researcher wrote two essays on similar themes, one by hand $(\mathrm{H})$ and one using a word processor $(\mathrm{T})$. The essays were written under timed conditions, and the researcher immediately noted a number of differences in approach apparently due to the difference in writing conditions. These were items such as

- (H) 'I found the structure quickly wandered in a way that I didn't really like; but it was too late (in simulated exam conditions) to change, even half way down page one.'

- (H) 'The opening was weak - I had to write it before I knew what I was introducing.'

- (T) 'I had expected that keying, plus editing including spellchecking for my many typos, would produce fewer final words per hour; I was surprised to discover I was wrong.'

- (T) 'I did a fair amount of cutting and pasting, shifting things around more than I could have done in a handwritten essay.'

Prompts along these lines were circulated to all students along with the invitation to participate. They were asked to consider beforehand how strongly they related to these items, or to identify others that they felt would be pertinent. Four students participated in the focus group, two male and two female. One was a mature student in the first year of the course, two were in their third year of a four year course, and one was a final year student. 
It quickly became clear in the group discussion that students found our questions confusing. They failed to see why we wished to contrast their approach to "writing" (word processed) coursework essays with their approach to handwriting examination essays. Their firm view was that examinations cannot really be compared with coursework. The key difference mentioned was the time limit which is imposed in an examination. Students worried that they were unfamiliar with how much they could type within a fixed time; and they worried that they could waste time making lots of small but essentially trivial changes to the word-processed text. For their coursework, the students readily recognised the importance of using good English, and of constructing a convincing argument. Yet for an examination, although a strong argument would be useful, they considered that the most important thing was to get lots of relevant facts down onto their script. Their view was that facts earn marks in an examination, and so anything that could distract you from getting those all important facts down on paper is to be avoided. The students did not raise typing speed as a barrier, or even as a very important consideration, when discussing the writing options which might be offered in their examinations.

These responses caused a re-plan. Information about real behaviour in examinations was needed. It was necessary to design acceptable ways of obtaining that data under examination conditions. Data about behaviour in examinations needed to be collected in, or immediately after, actual examinations.

During December 2010, as part of the routine examination diet, four first year classes (a total of 204 students) in the school of Divinity were offered the choice to handwrite or type their examination. A few weeks prior to the examination, students were given a demonstration of the software to be used, and were allowed unlimited access should they wish to familiarise themselves with the technology, which in this case included a spell-check facility. The software and examination hall procedures have been described fully elsewhere (Mogey et al, 2008). In brief, all students were in a single, invigilated examination hall; questions were provided on paper for all candidates and the examination timing was controlled by the invigilator. The examination software ensured that no access to the internet or local files was possible and that all data was encrypted and captured regularly by the local machine, before being submitted finally via wireless network. Scripts from students using laptops were printed, and distributed for marking along with the handwritten scripts.

Immediately after finishing their examination, all students in these classes were given a printed survey form which they were invited to complete in the examination hall. In order to reassure students that any information provided would not impact on their examination mark, the survey was anonymous. It was also designed to be quick to complete, recognising that students would be eager to leave the examination venue. The form was on a single side of A4 paper and consisted largely of 32 statements (Figure1) with which the respondents were invited to agree or disagree, while also providing some basic demographic and other data. Logistics required that the same survey was used regardless of whether the candidate had written by hand or keyboard.

[Figure 1 about here]

140 responses to the post examination survey were collected - a response rate of $69 \%$. Data were collated and analysed using minitab. The sample included 86 females and 43 males with 11 missing values for gender. The ages of respondents varied from 17 years to 50 years, with a median value of 19 years. Students were free to omit any item(s) they preferred not to answer, hence not all students responded to all questions, causing the totals in the tables which follow to vary slightly.

\section{Results}

The majority of students declined the offer to word-process their essays. Only 16 of the 204 candidates for the examination chose to type. 125 of the survey respondents chose to handwrite in the examination, 13 chose to type, 2 did not disclose their choice. 
Generally, male students were more likely to elect to type (Table 1), and the average age of those who elected to type was somewhat above the class average. Both results are clear, but are not strong enough to be statistically significant, perhaps due in part to the small sample sizes. Table 2 shows that $57 \%$ of the respondents, whether typing or handwriting, reported themselves as typing at least as fast as they could handwrite. The mean number of years they had been word processing was 11 years (cited range $3-23$ years).

[Table 1 about here]

[Table 2 about here]

Almost all the students (89\%) sought to correct their spelling mistakes, regardless of whether they were typing or writing by hand. They also tried to write fairly fluently: some $62 \%$ agreed with 'I just wrote as it came and then altered it as I went along' while $72 \%$ agreed with 'I tried not to go back and change things unless it was really important', and $54 \%$ went further and didn't go back and add things even though they realised they had missed things out.

However $58 \%$ did go back and change some words, and $21 \%$ moved one or more sentences. Additionally $76 \%$ of students agreed with the statement 'Exams mainly test memory'. While $66 \%$ of the students made a point of including lots of facts, and $70 \%$ tried to create a strong argument, $52 \%$ tried to do both (Table 3). A statistically significant association was found between making a detailed plan and trying to create a strong argument $(p=0.04$, chi-square test) and between making a detailed plan and moving one or more sentences ( $p=0.001$, chisquare test).

[Table 3 about here]

The small numbers of respondents who used their laptops means that comparing handwriters with keyboarders using a chi-squared test is unlikely to be reliable. Fisher's exact test was therefore used (recognising that the marginal totals were unknown in advance so the test is not strictly "exact" as the name would suggest, but a conservative approximation). Fisher's exact test does not yield a test statistic, only a probability. Items which provided strong evidence of differences between those who typed and those who used pen and paper are shown in table 4 . Additionally 7 items yielded results which while not being strong enough to be statistically significant, are indicative that there may be real differences in behaviour. These items, all with probabilities in the range $0.2>p>0.05$, are shown in table 5 .

[Table 4 about here]

[Table 5 about here]

No evidence of any difference in behaviour between handwriters and typists was found for a number of items, including those shown in table 6 .

[Table 6 about here]

Some students volunteered additional responses, either on the survey form or by e-mail:

'I have had a written exam and a laptop exam this semester. I think there will be a sensible difference between those two.'

'Just a quick email to say what a massive difference it made being able to sit my exam by laptop. I reckon it made about 15\% difference!'.

\section{Discussion and Conclusions}

The reasons students give for not taking up the offer to type in examinations vary. Few students have had any prior opportunity to sit examinations using a computer. They report that they are apprehensive about the reliability of the technology, and they are not confident 
that they will make best possible use of the available time. When the suggestion to allow students to type essay-type examinations is raised, typing ability is often cited as an immediate concern. This seems curious, given firstly that handwriting speed also varies (although arguably somewhat less than typing speed), secondly most students are now at least as proficient at typing as at handwriting (and the others can easily practice), but most critically that examinations are not simply about writing down as much as possible (Summers \& Catarro, 2003). Typing speed can surely be disregarded as a major concern when considering whether to allow use of word processors in essay-type examinations.

For examination essays, students may not understand what sort of response would be regarded as ideal. Indeed some aim to provide volume of facts in essay-type examinations rather than concentrating on their argument. Most students understand that coursework essays require attention to the structure and the argument; and that these features should be considered less critical in an examination essay seems curious; but may be due in part to the students in this study being first year, and inexperienced in a university context. A potentially critical difference which is not often raised by students concerns the process by which students go about composing examination essays, and whether this will differ if the student types or handwrites. The thinking processes involved in planning and developing the argument of the answer may differ. Significant differences between handwriters and typists on the items 'I think my exam paper will be easy for the marker to read' and 'My hand got tired by the end of the exam' perhaps validate the dataset rather than providing thought-provoking results in their own right. However the other two results in Table 4 demonstrate real differences in behaviours between typists and handwriters. They confirm that those students electing to type their examinations do in practice avail themselves of the option to edit and revise their text; they deliberately changed words and moved sentences in an effort to improve their essays. Others have found this type of behaviour to lead to an increase in the mark awarded (Oliver \& Kerr, 1993; Burke \& Cizek, 2006). Additionally, most students can type more than they can handwrite in an essay and length is correlated with quality for word processed scripts (Lovett et al, 2010). So, if students who type are more likely to go back and make changes to their text, and since text which has been more thoroughly revised tends to earn better marks, this all suggests that it will be to the advantage of all but the slowest keyboarders to choose to type.

Many of the concerns raised about typing essay-type examinations could be addressed through practice. Students worried that they would spend their time making too many cosmetic changes to the appearance of their text, but the data in table 6 suggests this was not felt to be a major issue for the students who chose to type in their examination. After the examination, $15 \%$ of the typists agreed with the statement "I spent a long time sorting out little things" compared with only $8 \%$ of handwriters. So while only a small proportion of the students agreed with the statement, it might tend to suggest that this could be more of an issue for those typing. While not dismissing this worry entirely, we should at least reassure students who elect to word process that being distracted to do lots of trivial things has not been found to be an issue for the majority of students using a keyboard. The worry about lack of ability to judge how much to type was also not a problem in practice, and could easily be learned with relatively little practice.

All these anxieties related to typing examinations might be considered curious given that traditional essay-type examinations are already known to disadvantage students in a multiplicity of ways (Brown, 2010). Examinations leave a great deal to chance, their criteria are often far from transparent, and arguably we often fail to prepare our students adequately for this special experience. We then further disadvantage them by asking them to compose their responses in a unique examination environment, where both the medium (pen and paper) and the time constraint are unlike their usual study framework. Nevertheless so far students have been reluctant to step into unfamiliar territory, and tend to prefer the status quo.

The students participating in this study represented only one year group (first year) and one discipline area. Limitations of the study include the disproportionate number of female to male responses (the sample comprised about $2 / 3$ female to $1 / 3$ male students) and the high proportion of more mature students, often studying for a second degree. These students may 
be more willing to engage in activities that others may perceive as risky. On the other hand, first year students, especially those coming straight from school, may have a poor understanding of what is expected in their first university examination essay, in comparison to students in later years.

The small number of respondents who elected to type, especially in comparison with than the number who handwrote, means the results must be viewed with a degree of caution. The students who chose to type are potentially more confident users of technology than their peers. In the focus group, the students to whom we spoke had told us that one important concern was their ability to judge how much to type for an examination essay. This concern was not reflected in the data collected from the examination. Those who chose to type perhaps already had sufficient familiarity with printed text, such that they felt able to estimate to their own satisfaction the quantity to be written.

The need to maintain the integrity of the examination system also imposes restraints. For example, in order to assure students that there was no possibility of their participation in this study impacting on their grade, it has not been possible to access any data about the quality of essay created either by hand or using a laptop.

Finally, where evidence of associations is indicated, no claims can be or are made about causality. Indeed it seems likely that the choice to handwrite or to type is confounded with many other factors. Ability, interest in the subject matter, the student's understanding of what is being sought from an essay-type examination answer and perceived performance on the day are all likely to influence survey responses.

The concern in this exploratory study was to gain information about how best to assess students for whom "writing" is nowadays principally a keyboard activity. If students are given the choice to handwrite or type, we would hope to advise and support them in making the choice which is best for them. There is much more still to learn and understand about how students approach writing examination answers, but the nature of high stakes assessment limits the amount of experimentation which can be undertaken, and requires some studies to be in artificially created examinations. It would be of interest to ask students to write two consecutive essays under conditions as near as possible to those of examinations, one typed and one handwritten, and then to reflect on any ways the two processes felt different and made different demands. Other areas that would benefit from further investigation include whether the time spent 'changing little things' is significantly greater for typists; the range and extremes of typing ability and any differences which may be associated with age or gender; and any evidence which can link writing behaviour in an examination with the grade achieved.

Since this study should be principally student focused, we are also left to pursue the rather worrying belief expressed by some students that staff marking examination essays and staff marking coursework essays are seeking something fundamentally different; that essay-type examinations are designed to test memory rather than the ability to construct a coherent argument; and that in an examination all you really need to do is churn out lots of facts without showing your ability to think. There is plenty of support and guidance provided in preparation for examinations, but for first year students in particular, where they are arguably still in transition from school (where the requirements and expectations in examinations might have been different), there is much still to discover about assessment at tertiary level. That possibility merits closer attention.

It is to be hoped that future research into the process of assessment featuring examination essays will devote attention to the possibility that they call for the exercise of special, and perhaps not particularly relevant, abilities; that the alignment of examination essays with intended learning outcomes is possibly less true than is the case with assignment essays; and that the requirement to produce a finished piece of writing in a relatively short time may preclude display of the very learning and development which the examination ought to be assessing.

We have suggested that any move to more widespread adoption of word processing in examinations should be preceded and supported by practice, since without prior experience 
in an examination-like situation; many students will prefer to stick with that which is familiar. Less experienced typists might find it useful to focus some of their practice time on getting a feel for roughly how much content they can type in a fixed time and how many screens of text that will generate. It would also be logical to combine time spent becoming familiar with the technology with guidance or clarification, from tutors and perhaps from former students of the course concerned, about what constitutes a high quality examination response. Researchers should help students to understand what is being sought from them, and to support them to respond accordingly; and they should evaluate the effectiveness of those arrangements.

Much of the concern expressed by students about moving to word processing in an examination was due to their reactions to the time constraint, prompting associated questions for researchers, Is it really necessary to have a rigid time limit for an examination? Why not allow an extra 5 minutes for a student who wants it? Why does everyone have to put their pens down or stop typing at or before the precise moment allotted? It is recognised that writing to a deadline is sometimes a reality; but such a deadline is rarely quite as rigid as for an examination. If the point of an examination is to demonstrate understanding of content and the ability to create a high quality argument without collaboration, and especially if we wish to allow our students to produce and show their best work, then why impose a time limit which in turn causes the students to worry, to adjust their strategies, and potentially to underperform?

Extrapolating from the results leads to the suggestion that, for all except those few students for whom using a word processor may remain a real challenge, we should be actively encouraging students to take up any option to type for essay-type examinations. A student who opts to type will be able to concentrate in their usual manner, on producing a high quality, well-structured essay, which the examiner can read with ease. A student who opts to handwrite is most likely putting themselves at a real disadvantage in displaying their learning. Yet, the students in this study were clearly not keen to key; so few took up the option of typing. We currently offer our students (those without special needs) no choice at all in an examination; we require ('force') them to write their responses by hand. Whether or not we wish to offer students the choice to write or to type, or whether we wish to move to essay-type examinations on computer as the default position, it is clear that there is much that we need to do to persuade students that this could be 'a good thing'.

\section{Acknowledgements}

The students and staff of the School of Divinity who have been most supportive in giving their time and opinions over many months; to Dai Hounsell for comments and conversations, including one which questioned why exams have a time limit, and to the reviewers of the original version of this paper for their helpful, detailed and constructive comments. We are especially grateful to Lynne Baldwin who as editor, devoted much time, care and creativity to help us to convey our message in a much more effective form than in the original submitted draft.

\section{References}

Barrett S. (1999) 'Question Choice: does marker variation make examinations a lottery?', HERDSA International Conference Melbourne 12-15 July.

Brown, G. (2010) 'The validity of examination essays in higher education: issues and responses', Higher Education Quarterly 64(3): 276-291.

Burke, J. and Cizek, G. (2006) 'Effects of composition mode and self-perceived computer skills on essay scores of sixth graders', Assessing Writing 11(3): 148-166. Callan, R. (1999) 'Effects of matching and mismatching students' time of day preferences', The Journal of Educational Research 92(5): 295-299.

Carless, D. (2009) 'Trust, distrust and their impact on assessment reform', Assessment and Evaluation in Higher Education 34( 1): 79-89.

Cassaday, H., Bloomfield, R. and Hayward, N. (2002) 'Relaxed conditions can provide memory cues in both undergraduates and primary school children', British Journal of Educational Psychology 72(4): 531-547. 
Chamorro-Premuzic, T. and Furnham, A. (2002) 'Neuroticism and "special treatment" in university examinations', Social Behavior and Personality: An International Journal 30(8): 807-811.

Chen, J., White, S., McCloskey, M., Soroui, J. and Chun, Y. (2011) 'Effects of computer versus paper administration of an adult functional writing assessment', Assessing Writing 16(1): 49-71.

Clifford, M. (1990) 'Students need challenge, not easy success', Educational Leadership 48(1): 22-26.

Connelly, V., Dockrell, J. and Barnett, J. (2005) 'The slow handwriting of undergraduate students constrains overall performance in essay exams', Educational Psychology 25(1): 99107.

Davies, B., Scriven, M. and Thomas, S. (1981) The evaluation of composition instruction. Point Reyes, CA: Edgepress.

Haas, C. (1989) 'How the writing medium shapes the writing process: effects of word processing on planning', Research in the Teaching of English 23 (2): 181-207

Hartley, J. (1993) 'Writing, thinking and computers', British Journal of Educational Technology 24(1): 22-31

Hartley, J. and Nicholls, L. (2008) 'Time of day, exam performance and new technology', British Journal of Educational Technology 39(3): 555-8

Horkay, N., Bennett, R., Allen, N., Kaplan, B. and Yan, F. (2006) 'Does it matter if I take my writing test on computer? An empirical study of mode effects in NAEP', The Journal of Technology, Learning and Assessment 5(2): 4-49.

Hounsell, D. (2005) 'Contrasting conceptions of essay-writing', in: Marton, F., Hounsell, D. and Entwistle, N., (eds.) The Experience of Learning: Implications for teaching and studying in higher education, 3rd edition, pp. 106-125. Edinburgh: University of Edinburgh, Centre for Teaching, Learning and Assessment.

Lamprianou, I. (2008) 'High Stakes Tests with Self-Selected Essay Questions: Addressing Issues of Fairness', International Journal of Testing 8(1): 55-89.

Lovett, B., Lewandowski, L., Berger, C., and Gathje, R. (2010) 'Effects of response mode and time allotment on college students' writing', Journal of College Reading and Learning 40(2):

64-79.

MacCann, R., Eastment, B. and Pickering, S. (2002) 'Responding to free response examination questions: computer versus pen and paper', British Journal of Educational Technology 33(2): 173-188.

MacKenzie, I. S. and Soukoreff, R. W. (2002) 'Text entry for mobile computing: Models and methods, theory and practice', Human-Computer Interaction 17(2-3):147-198.

Maclellan, E. (2004) 'Authenticity in assessment tasks: a heuristic exploration of academics' perceptions', Higher Education Research and Development 23(1): 19-33.

Miller, C. and Parlett, M. (1974) Up to the Mark: a study of the examination game. Guildford: Society for Research into Higher Education.

Mogey, N., Sarab, G., Haywood, J., van Heyningen, S., Dewhurst, D., Hounsell, D. and Neilson, R. (2008) 'The end of handwriting? Using computers in traditional essay examinations', Journal of Computer Assisted Learning 24(1): 39-46.

Mogey, N., Paterson, J., Burk, J. and Purcell, M. (2010) 'Typing compared with handwriting for essay examinations at university: letting the students choose', ALT-J Research in Learning Technology 18(1): 29-47.

Norton, L. S. and Hartley, J. (1986) 'What factors contribute to good examination marks? The role of note taking in subsequent examination performance', Higher Education 15 (3/4): 355371.

Oliver, R. and Kerr, T. (1993) 'The impact of word processing on the preparation and submission of written essays in a tertiary course of study', Higher Education 26(2): 217-226. Ramsden, P. (1992) Learning to Teach in Higher Education. London: Routledge.

Struyven, K., Dochy, F. and Janssens, S. (2002) 'Students' perceptions about assessment in higher education: a review', presented at the Joint Northumbria/ Earli SIG Assessment and Evaluation Conference: Learning communities and assessment cultures, University of Northumbria at Newcastle, August 28 - 302002.

http://www.leeds.ac.uk/educol/documents/00002255.htm [accessed 18 Feb 2011]

Summers, J. and Catarro, F. (2003) 'Assessment of handwriting speed and factors influencing written output of university students in examinations', Australian Occupational Therapy Journal 50(4): 148-157. 
Whithaus, C., Harrison, S.B. and Midyette, J. (2008) 'Keyboarding compared with handwriting on a high stakes writing assessment: student choice of composing medium, raters'

perceptions, and text quality', Assessing Writing 13(1): 4-25.

Figure 1: Full list of post exam survey prompts

Students were invited to strongly agree / agree / disagree / strongly disagree with each of these items. Items could be left blank as desired.

When the exam started I felt confident about how I should/would use my time

I had pretty much guessed some of the questions on the paper

I started writing/typing as quickly as I could

I thought very carefully before I started

I made rough notes or a basic plan

I took time to make a detailed plan

I was able to use some answers which I had prepared in detail

I had prepared some answers but couldn't really use them

I just wrote as it came and then altered it as I went along

I tried not to go back and change things unless it was really important

I corrected spelling mistakes if I knew about them

I went back and changed some words to improve my text

I moved one or more sentences to improve my text

I spent a long time sorting out little things

I realised I missed things out but felt it was too late to change them

I made a point of creating a strong argument

I made a point of including lots of facts

I did the introduction(s) first

I did the conclusion(s) last

I read through/checked my work

I ran out of time

My hand got tired by the end of the exam

My brain got tired by the end of the exam

I found myself distracted by others in the exam hall

I feel pleased with how I used my time

I think I have written more than if I had had to handwrite/type

I found it easy to judge when I had written enough for each question

My writing style in the exam was much the same as for coursework

I think my mark will be a fair reflection of my ability in this subject

I think my exam paper will be easy for the marker to read

Exams mainly test memory

Good English and grammar are important in an exam essay

Table 1: Some demographic data from the sample $(n=127)$

\begin{tabular}{|l|c|c|c|}
\hline & Male (n/\%) & Female (n/\%) & mean age (Years) \\
\hline Handwrite & $36(84 \%)$ & $78(93 \%)$ & 21.3 \\
\hline Type & $7(16 \%)$ & $6(7 \%)$ & 23.8 \\
\hline Total & 43 & 84 & 21.6 \\
\hline
\end{tabular}

Table 2: Self reported typing speed

\begin{tabular}{|l|c|}
\hline & $\mathrm{n} / \%$ \\
\hline I handwrite faster than I type & $29(21 \%)$ \\
\hline I type faster than I can handwrite & $49(36 \%)$ \\
\hline There's not much difference between my writing and my typing speed & $42(31 \%)$ \\
\hline I don't know & $16(12 \%)$ \\
\hline TOTAL & 136 \\
\hline
\end{tabular}

Table 3: Number (and \% of total) students who agreed or disagreed with the statements 'I made a point of including lots of facts' and 'I made a point of creating a strong argument' 


\begin{tabular}{|l|r|r|r|c|}
\hline \multicolumn{2}{|c|}{} & \multicolumn{3}{|c|}{ I made a point of including lots of facts } \\
\hline \multirow{3}{*}{$\begin{array}{l}\text { I made a point of creating a } \\
\text { strong argument }\end{array}$} & & Agree & Disagree & Total \\
\cline { 2 - 5 } & Agree & $67(52 \%)$ & $23(18 \%)$ & $90(70 \%)$ \\
\cline { 2 - 5 } & Disagree & $18(14 \%)$ & $21(16 \%)$ & $39(30 \%)$ \\
\cline { 2 - 5 } & Total & $85(66 \%)$ & $44(34 \%)$ & 129 \\
\hline
\end{tabular}

Table 4: items with statistically significant differences in responses when comparing students using pen and paper $(H)$ with students using laptops $(T)$

\begin{tabular}{|l|l|c|}
\hline Item & $\begin{array}{l}\text { Fisher's } \\
\text { exact test } \\
\text { result }\end{array}$ & $\begin{array}{l}\text { Stronger } \\
\text { agreement } \\
\text { from group }\end{array}$ \\
\hline I think my exam paper will be easy for the marker to read & $\mathrm{p}=0.0156$ & $\mathrm{~T}$ \\
\hline I went back and changed some words to improve my text & $\mathrm{p}=0.00083$ & $\mathrm{~T}$ \\
\hline I moved one or more sentences to improve my text & $\mathrm{p}<0.0000$ & $\mathrm{~T}$ \\
\hline My hand got tired by the end of the exam & $\mathrm{p}<0.0000$ & $\mathrm{H}$ \\
\hline
\end{tabular}

Table 5: items where differences in responses are non-significant but still suggest possible differences between students using pen and paper $(H)$ with students using laptops $(T)$

\begin{tabular}{|l|c|}
\hline Item & $\begin{array}{l}\text { Stronger } \\
\text { agreement } \\
\text { from group }\end{array}$ \\
\hline My writing style in the exam was much the same as for coursework & $\mathrm{T}$ \\
\hline I made a point of creating a strong argument & $\mathrm{T}$ \\
\hline I made a point of including lots of facts & $\mathrm{T}$ \\
\hline I did the introduction(s) first & $\mathrm{H}$ \\
\hline I did the conclusion(s) last & $\mathrm{H}$ \\
\hline My brain got tired by the end of the exam & $\mathrm{H}$ \\
\hline I feel pleased with how I used my time & $\mathrm{T}$ \\
\hline
\end{tabular}

Table 6: items with no evidence of differences in responses between students using pen and paper $(\mathrm{H})$ with students using laptops $(\mathrm{T})$

\begin{tabular}{|l|c|c|}
\hline & $\begin{array}{c}\mathrm{H} \\
\mathrm{n}(\% \text { handwriters) }\end{array}$ & $\begin{array}{c}\mathrm{T} \\
\mathrm{n}(\% \text { typists) }\end{array}$ \\
\hline I spent a long time sorting out little things & $10(8 \%)$ & $2(15 \%)$ \\
\hline $\begin{array}{l}\text { I found it easy to judge when I had written enough } \\
\text { for each question }\end{array}$ & $60(55 \%)$ & $7(58 \%)$ \\
\hline $\begin{array}{l}\text { I realised I missed things out but felt it was too late } \\
\text { to change them }\end{array}$ & $65(54 \%)$ & $6(50 \%)$ \\
\hline
\end{tabular}

